\title{
Evaluation Framework for Blended Learning Courses: A Puzzle Piece for the Evaluation Process
}

\author{
Lúcia Pombo \& António Moreira \\ University of Aveiro, Portugal
}

\begin{abstract}
This article discusses the process of evaluation in bLearning courses, namely the objects of evaluation, discussing their relevance according to the opinion of international experts in Online Teaching and Learning, taking into account the curricular proposals of the three cycles of Higher Education (HE). The question 'what should be evaluated?' is one puzzle piece of the whole process of evaluation. The other pieces should be articulated among themselves and combined, namely 'who should evaluate?', 'how and when to evaluate?' and 'what is evaluation for?' Those questions were asked in a survey conducted with 35 international experts with an average experience of 13 years in the area, from international HE institutions (HEls) that offer this kind of courses. The study highlights the need of HEls to reassess their approach to the quality assurance of bLearning courses, and brings some contributions to those who are in charge of blearning courses, providing a useful framework for evaluation. Furthermore, this paper contributes to the knowledge on educational technology and raised new issues for further research and discussion.
\end{abstract}

Keywords: Evaluation objects; Benchmarks; Blended learning; Technology-based environments; Higher Education

\section{Introduction}

Nowadays, blended Learning (bLearning) is widely used in many Higher Education Institutions (HEls), especially those that have embraced distance education and any other form of eLearning as one of their major institutional and teaching efforts (Mortera-Gutierrez, 2004). The term bLearning can be interpreted in various ways. Blend is to mix or combine things together, depending on the focus; for instance, a blend of: (i) pedagogical strategies, combining problem solving activities and debates, as proposed by Donnelly (2006); (ii) supporting technologies, using different tools, such as forum, podcast, wiki, blog, and twitter, as referred by Walker \& Beats (2008); or (iii) delivery modes in which face-to-face (f2f) and online activities are organized taking the strengths of both approaches into play (Garrison \& Vaughan, 2008; Stacey \& Gerbic, 2008). In this paper, we adopt Graham's (2004) definition because bLearning is taken as the integration of f2f activities with technology-supported activities at a distance (Graham, 2004; Conole et al., 2007). Theoretically, by practicing bLearning the conveniences of online courses are gained without the loss of $\mathrm{f} 2 \mathrm{f}$ contact. Thus, a learning environment is created which is richer than either a traditional f2f environment or a fully online environment (Harding, Kaczynski, \& Wood, 2005). 
Mixing technology-enhanced learning experiences with other, more traditional, learning experiences would have been seen as a normal practice in the mainstream of developments in computer-assisted learning in HE during the last 30 years of the 20th century (Bliuc, Goodyear, \& Ellis, 2007). Thus, bLearning is pervading $\mathrm{HE}$, compelling educators to confront existing assumptions of teaching and learning. Lecturers adopt bLearning for several reasons: (i) they recognize that students may not be able to deal with a fully online course; (ii) they wish to introduce students to technology; (iii) they propose to offer extra support to weaker students; (iv) they intend to reduce the $\mathrm{f} 2 \mathrm{f}$ component of the teaching so that part time students and those with family responsibilities have better access to learning; or (v) for many universities the move to bLearning occurs for financial and staff management reasons (Harding, Kaczynski, \& Wood, 2005). Independently of the above-mentioned reasons as to why bLearning is more and more used in $\mathrm{HE}$, the imperative for quality assurance (QA) initiatives for eLearning, and particularly for bLearning in HE, is highly acknowledged (Weaver, Spratt, \& Nair, 2008; Ireland, Correia, \& Griffin, 2009).

HEls are looking for QA for their e-Learning or bLearning offerings. For example, the European Association of Distance Teaching Universities (EADTU) is an institutional network for open and flexible HE. At present its membership comprises the open and distance teaching universities, national consortia which connect conventional universities and associate members from nonEuropean countries. Its membership covers over 200 universities and around three million students across Europe. E-xcellence, EADTU, is leading a European movement on QA in e-learning, more specifically, the building of an e-learning benchmarking community of Associates in Quality. The E-xcellence Associates focus on the improvement of four priority elements of progressive HE: Accessibility, Flexibility, Interactiveness, and Personalization (http://www.eadtu.nl/excellencelabel/default.asp?mMid=1). The EADTU strategies fit into the European Area of HE (Bologna Declaration) and the Lisbon Strategy of the EU, the national and European policies with regard to lifelong learning, and into institutional strategies for the lifelong development of high quality competences for European citizens. Another example is the Open \& Distance Learning Quality Council (ODLQC), which is the British guardian of quality in open and distance learning as it guarantees quality in all open or distance learning, including home study, correspondence courses, e-learning, blended and work-based learning (http://www.odlqc.org.uk/index.htm).

However, there are some questions to be answered. What should be evaluated? What should be the benchmarks for QA? Is it cost effectiveness? Is it the practical benefits for particular groups of students? Is it the attitude of students? Is it the improvement in learning? How can we assure the quality of those particular courses? In this paper we will look at the four components of the puzzle that constitute our evaluation framework (Pombo \& Moreira, 2011b), looking further at a single piece, which encloses the evaluation objects, trying to answer the question "What should be evaluated in bLearning courses?", consulting international experts in the area.

Most studies about evaluation of teaching concerning the specificities of bLearning tend to report more varied aspects of the students' learning experience (Bliuc, Goodyear, \& Ellis, 2007; Kaznowska, Rogers, \& Usher, 2011), and a small number of studies take a more holistic approach considering also academics or lecturers' perspectives. Moreover, among several and different terms, concerning the areas of online, eLearning, bLearning or hybrid Learning, we select the mode of bLearning to explore in this paper because this study is part of a wider project that seeks to develop and test evaluation and assessment strategies in bLearning contexts. This study is 
related to previous ones that examined the evaluation practices of teaching and learning, concerning the perceptions of national course directors (Pombo \& Moreira, 2010), and national lecturers (Pombo \& Moreira, 2011a).

This main aim of this paper is to discuss the process of evaluation in bLearning courses, namely the objects of evaluation, discussing their relevance according to the opinion of international experts in Online Teaching and Learning, taking into account the curricular proposals of the three cycles of Higher Education (HE).

\section{Evaluation Objects and Quality Benchmarks}

Evaluation is a procedure that involves the comparison between a real situation and what is (highly) expected; and it is guided by a theoretical referential (Hadji, 2001) about what is expected of the evaluation object. An analogy that we can visualize is a cat that looks at a mirror and what it actually sees is a strong lion; this means that evaluation is highly related to improvement or getting better. Evaluation is therefore taken as a process of finding ways to improve the quality of the object under evaluation, i.e., quality enhancement.

It seems paradoxical to talk about the quality of bLearning as quality is often linked with checking against externally imposed standards. However, quality can also be understood from a development-oriented perspective, which means enabling learners to develop themselves in their own learning process and consequently produce better results as far as quality is concerned.

Growing experience and analysis of online learning are revealing that new forms of teaching require new quality criteria. Most of our standards for the delivery of instruction never included these new technologies and communication tools. Standards and methods that have been studiously crafted to teach in $\mathrm{f} 2 \mathrm{f}$ sessions cannot simply be doubled-clicked into an online environment. Although online learning exhibits many benefits in terms of flexible interaction, availability of various media and tools, etc., there are still some obstacles to the design of online learning solutions (Karadeniz, 2009).

While online learning ensures flexibility and the development of competences that are difficult to ensure in a real class setting, $\mathrm{f} 2 \mathrm{f}$ education enables social interaction that is required as guidance for students (Ugur, Akkoyunlu \& Kurbanoglu, 2011). The key contribution of the present paper is a discussion around the main benchmarks that have to be taken into account for the evaluation of the quality of bLearning courses to ensure effective, efficient and flexible learning for the learner. Little is known about the practices related to the evaluation of teaching and learning in bLearning contexts, namely answers to questions like who should evaluate?, how and when to evaluate?, what should be evaluated?, and what to evaluate for? In our point of view these four pieces should be articulated in order to provide a practical tool to help students, parents, educators, and policymakers to create, use and evaluate bLearning courses (see Figure 1). 


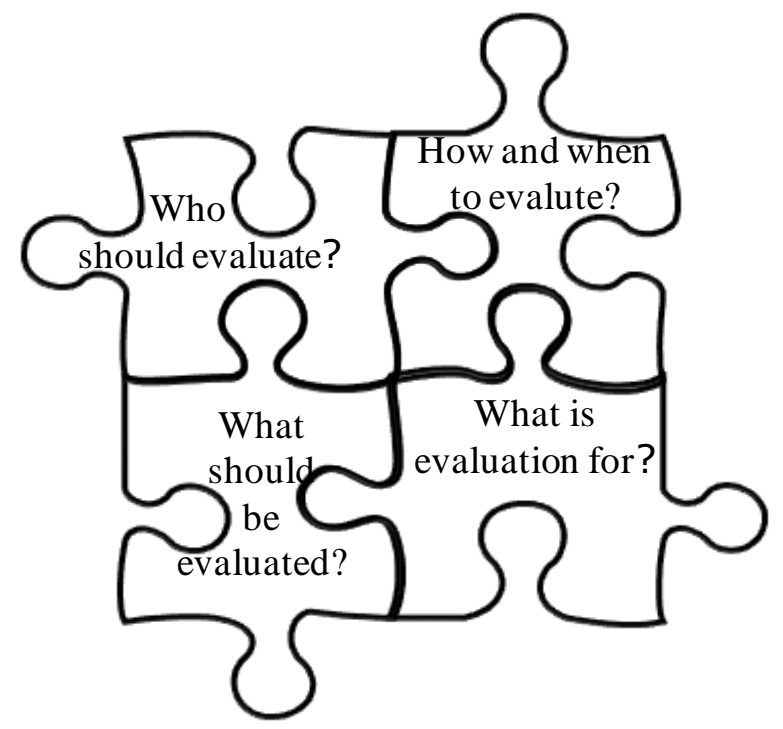

Figure 1. Four Puzzle Pieces of Evaluation

Each puzzle piece includes several factors that are fully explained in the model proposed by Pombo and Moreira (2011a). This article will focus especially on the piece "what should be evaluated?" e.g., what should be the evaluation benchmarks or the evaluation criteria in order to assure and enhance the quality of teaching and learning. In this piece the model includes three main categories: (i) Teaching (which includes teaching but also the lecturers), (ii) Learning, and (iii) Resources. These three categories should be connected together, working as an engine (see figure 2 ), e.g., if one category is not working well, it will affect the functioning of the whole process.

In the 'Teaching' category, we include the following criteria: (i) the relevance of the proposed activities/tasks; ii) the quality of the teaching materials provided; (iii) the communication tools used; (iv) the organization of the curricular units (e.g. if the activities meet the objectives, etc.), among others. Concerning specifically the 'Lecturers' sub-category we include: (i) scientific or pedagogical competence; (ii) dynamism and monitoring in conducting $\mathrm{f} 2 \mathrm{f}$ and online activities; (iii) skills at motivating students; (iv) quality of feedback given to students, etc. In the 'Learning' category, we may evaluate: (i) the interactions (communication between students) within groups; (ii) the interactions (communication between students) among groups; (iii) the assessment strategies adopted; (iv) the development of specific competences defined for the curricular unit; (v) the development of transversal competences defined for the curricular unit (e.g. development of values and attitudes, autonomy, capacity for research and group work, etc.); (vi) type and adequacy of assessment tools/tasks/products (if the literature tools are appropriate to the proposed tasks), etc. As to the 'Resources' category we may evaluate: (i) support provided by nonteaching staff; (ii) the support structure (LMS, network, bandwidth, help desk); (iii) logistics (availability of computers, wireless access, adequate rooms...), etc.

In this contribution, international researchers/senior teachers/lecturers with experience in bLearning were asked about their understanding of the evaluation criteria of a course, and the whole processes, obtaining a wider spectrum of specialized opinions about the importance of each factor of the three categories comprised in the puzzle piece "What should be evaluated?". 


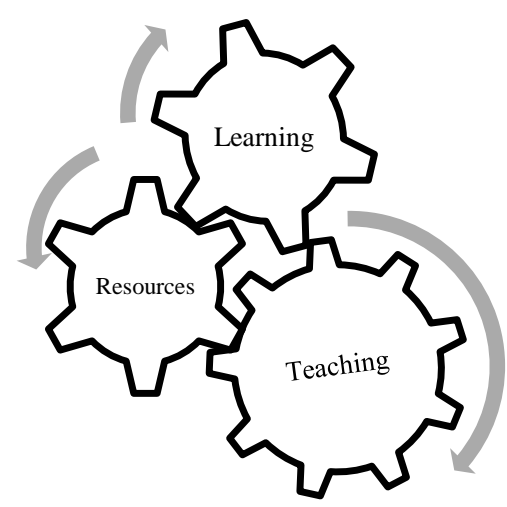

Figure 2. The Engine for "What Should Be Evaluated" Puzzle Piece, with the Three Categories Functioning Together: Teaching, Learning, and Resources

\section{Methodology}

The study had an exploratory and descriptive nature. The research method is mixed, using mainly quantitative techniques of data collection and analysis (Creswell, 2003). The aim was to gather the views of the experienced international experts with a wide experience in bLearning about the objects or benchmarks that should be taken into account for the bLearning evaluation, so that this could be helpful to decision makers when planning criteria for quality bLearning courses.

The data used in the study was collected through the administration of an online questionnaire to experts (researchers/lecturers) with experience in bLearning at international level. The selection of experts had into account their experience and expertise in bLearning courses, comprising three different criteria: (i) with publications or participation in projects related to bLearning; (ii) from different countries involving the five continents; and (iii) with availability to participate in the study by answering the questionnaire.

The instrument was sent directly using the institutional e-mail of each respondent, personalizing the request and raising the importance of filling in the form, exposing the main aims of the study. The questionnaire was answered by 35 of the 50 contacted experts. The experts who participated in the study had an average of experience in bLearning of 13 years, (between 3 and 35 years of experience) and their main function in his/her institution was: professor, researcher, technology director, department head, director of distance education, and coordinator of ICT. Their major research interests were all related to Distance Education, such as, specifically: online learning, elearning, social networking, information and communication technologies, integration of technology in the curriculum, evaluation of educational technology, e-learning and TEL (Technology Enhanced Learning), computer-supported collaborative learning, monitoring of students, feedback, evaluation, design and development of learning environments, among others. The questionnaire designed for the above-mentioned purpose included 4 main topics in a total of $54 \mathrm{closed} /$ structured questions, except for the items where other topics that were not considered in the questionnaire (a total of 7 open questions) were required from respondents if they so 
wished. The instrument was divided into the four dimensions contemplated in Figure 1 . The questions were: (i) what the evaluation goals should be?; (ii) who should be involved in the evaluation for the improvement of the course?; (iii) how and when the evaluation of the modules should be made?; and (iv) what should be evaluated?

The findings presented here only show the analysis of the closed questions about the experts' perceptions of what should be changed in the evaluation in order to improve the quality of the course. The specific question was: 'what should be evaluated?'. The data were analysed using quantitative techniques, namely descriptive statistics, using 'Paws Statistics 18' and 'Microsoft Excel'.

\section{Findings}

International experts were asked about the evaluation benchmarks that they think relevant to be implemented in their courses, i.e. what should be evaluated? (Figure 3).

When experts were asked about what should be changed in the evaluation in order to improve the quality of the course, i.e. which evaluation objects should be adopted in HEls, most experts (26 respondents, 74\%), in the 'Teaching' category, mentioned the "pertinence of the tasks" and the "organization of modules" (25 respondents, 71\%) as very relevant. Some respondents (21 respondents, 60\%) think that the "organization of online sessions" is 'very relevant', when compared to "organization of $\mathrm{f} 2 \mathrm{f}$ sessions" (18 respondents, $51 \%$ ). This is in accordance with Jara and Mellar (2009) who mentioned that in eLearning courses, whether fully online or blended, the risk of a lack of ownership, and a shifting of responsibilities between parties may affect the quality of the course.

When asked about the 'lecturers' evaluation', most respondents mentioned their "quality feedback" (27 respondents, 77\%) as very relevant. This is in accordance with Hummel (2006) who defends that feedback can be considered an important, if not the most important support mechanism in a variety of educational contexts as bLearning calls for individualized support to reach the learner's needs of heterogeneous groups. Moreover, a higher number of experts (23 respondents, $66 \%$ ) considered very relevant the "pedagogical competence" when compared to the "scientific competence" of lecturers (13 respondents, $37 \%$ ).

With respect to the 'Learning' category, small differences were pointed out concerning the high relevance of benchmarks. For example, 22 experts (63\%) mentioned the 'students' communication within groups" and 20 experts (57\%) declared the "students' communication between groups" as very relevant. 21 respondents (60\%) mentioned the "development of specific competences" and 20 respondents (57\%) referred the "development of transversal competences" as very relevant categories. Moreover, 21 respondents pointed out also the "type and adequacy of assessment instruments" as very relevant. 


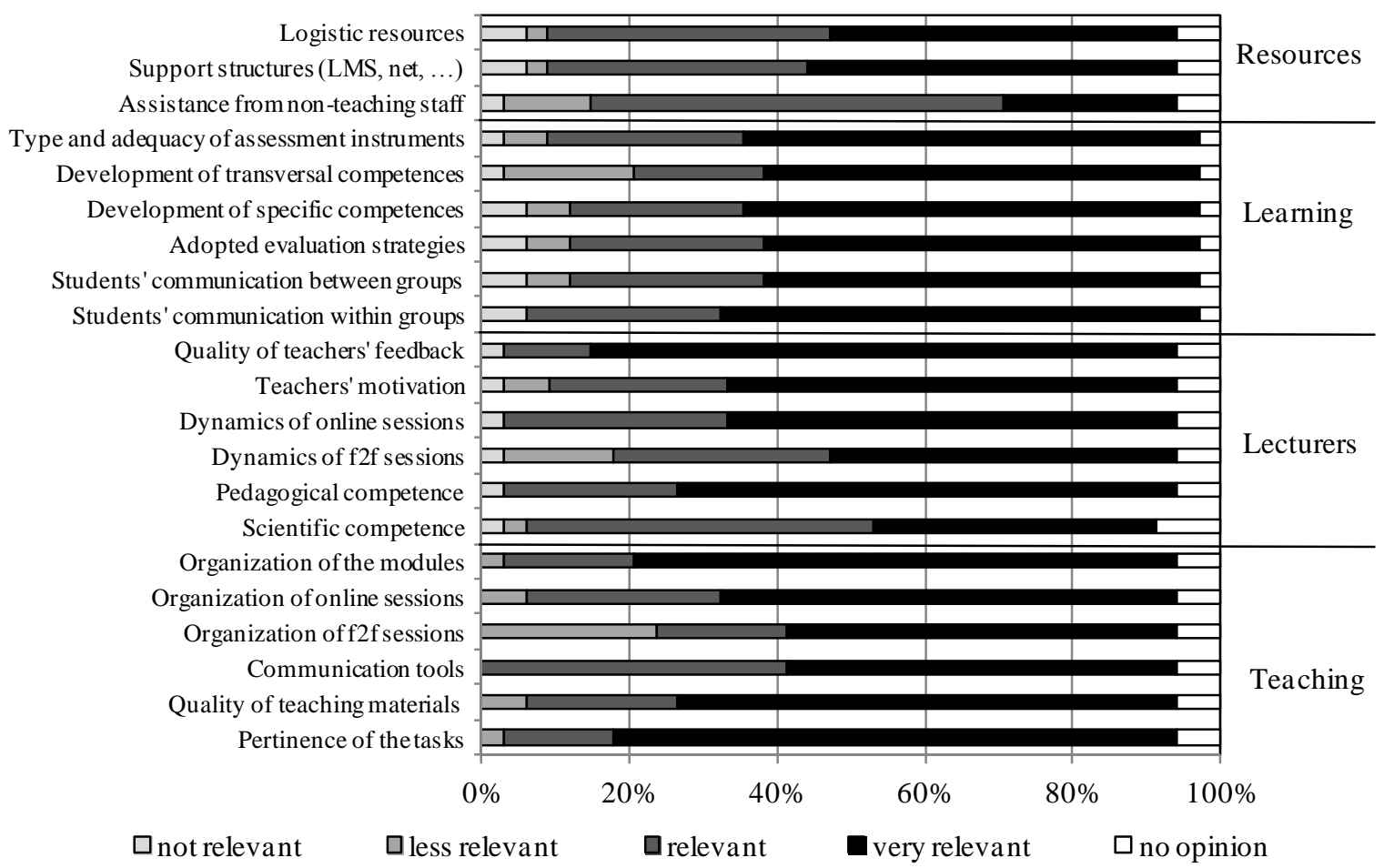

Figure 3. Lecturers' Opinions about 'What Should Be Evaluated?' in Order to Assure and Enhance Their Teaching and Learning Quality

Finally, concerning the 'Resources' category, "support structures" and "logistic resources" were mentioned by 17 and 16 respondents ( 46 and 49\%), respectively, as very relevant, while only 8 respondents (23\%) mentioned the "assistance from non-teaching staff" as very relevant. So, these kinds of benchmarks seem to have less relevance when compared with the other benchmarks mentioned above.

\section{Conclusion}

HEls are increasingly making use of technology to support the delivery of their courses and, in particular, expanding their eLearning provision through the use of web-based technologies for delivering online and bLearning courses. As so, governments, QA agencies and other professional bodies are becoming interested in identifying the appropriate ways to assure the quality of this provision (Parker, 2008). The need for determining and maintaining quality in the process of designing, developing and delivering bLearning courses is becoming an important issue for HEls worldwide. Course leaders and the other directly involved entities need to distribute responsibilities explicitly and collect feedback to be used for the enhancement of the quality of the course. Online learning evaluation should be implemented to serve a variety of functions, such as to explore the potential effectiveness of online courses, compare online courses, and also as a formative tool to guide and inform the development of online learning materials. 
The main aim of this study was to gather views of experienced international experts with a wide experience in bLearning about the objects or benchmarks that should be taken into account for the bLearning evaluation, so that this could be helpful to decision makers when planning criteria for quality bLearning courses.

As the main result, for the most part, bLearning not only centers the learners as receivers but also as active actors which take part in the definition and evaluation of the quality of learning resources and processes (Pombo \& Moreira, 2011a). The experts agree that bLearning requires a stronger definition of planning strategies, namely the organization of the modules. It is also noted that they emphasize the coordination of online sessions as more relevant than the $\mathrm{f} 2 \mathrm{f}$ sessions, which is in accordance with Jara and Mellar (2009) who mentioned that in eLearning courses, whether fully online or blended, the risk of a lack of ownership, and a shifting of responsibilities between parties may affect the quality of the course.

Moreover it is also highlighted that communication between the people involved (within and between students and among students and lecturers) has to be considered when evaluating the course, as the opportunities to directly interact with students become more limited and tutors increasingly have to depend on the students' willingness to login and respond in order to establish communication with them (Walmsley, 2004).

Experts also gave special attention to the pedagogical competence of lecturers rather than their scientific competence, which could be related to the fact that, in this mode of teaching, academics work in less isolated ways than in traditional provision and the development of courses usually relies on the collaboration of a group of people, of different specializations, which runs against the normal practices of vertical units of organization traditional of HEls. The quality of feedback is also largely mentioned as a very relevant criterion, which is in accordance with Hummel (2006) who defends that feedback can be considered an important, if not the most important, support mechanism in a variety of educational contexts, as bLearning calls for individualized support to reach the learner's needs of heterogeneous groups.

The type and adequacy of assessment instruments is also considered very important, because of the particularities of this kind of provision that can allow a more in-depth, continuous and accurate monitoring of activities, when compared to more traditional provision, as content, resources and communication among participants are mainly text-based and usually automatically saved in the online environment (Fielding et al., 2004), so the assessment strategies to adopt in bLearning should also take that into consideration.

In addition, our evaluation framework recommends, also considering results from previous studies (Pombo et al., 2009; Pombo, Loureiro, \& Moreira, 2009; Pombo \& Moreira, 2010), that quality evaluation of bLearning should be focused on the learning process, during the development of the tasks, and not only at the end. When it comes to evaluation, subjectivity decreases when there are several evaluators; evaluation should be made not only by the lecturer but also by students and teaching peers. Using more than one instrument allowing for triangulation of data and using several different quality benchmarks having in mind the improvement of teaching and learning quality, also guarantees the quality of the course. 
The purpose of this case study was to bring some contributions to those who are in charge of bLearning courses, providing a useful framework that covers all aspects of quality assurance of teaching and learning. The challenge was to identify those benchmarks that are essential for quality in bLearning courses, in contrast to those benchmarks that contribute to support the teaching/learning process, but are not necessary or required to ensure quality, such as the assistance of non-teaching staff, or support structures.

The work in this area could be improved adding and comparing the opinion of academic staff, tutors, administrators, students, support staff and developers/designers. Their opinion could also be complemented to what really happens in the field comparing the way evaluation is made with the way evaluation should be conducted in order to enhance the quality of the courses, and consequently improve the quality of teaching and learning in HEls.

\section{Acknowledgements}

The authors would like to thank all the international researchers/experts who kindly participated in the study. This study was supported by the Research Centre for Didactics and Technology in Teacher Education, University of Aveiro, Portugal.

\section{References}

Bliuc, A.C., Goodyear, P., \& Ellis, R.A. (2007). Research focus and methodological choices in studies into students' experiences of blended learning in higher education. Internet and Higher Education, 10, 231-244.

Conole, G., Oliver, M., Falconer, I., Littlejohn, A., \& Harvey, J. (2007). Designing for learning. In G. Conole \& M. Oliver (Eds.). Contemporary perspectives in e-learning research: Themes, methods and impact on practice (pp. 101-120). London: Routledge.

Donnelly, R. (2006). Blended problem-based learning for teacher education: lessons learnt. Learning, Media and Technology, 31(2), 93-116.

Fielding, A., Harris, S., \& King, S. (2004). A view from the shop floor. Learning and Teaching in Action, 3(2), available at: www.celt.mmu.ac.uk/ltia/issue8/fielding.pdf (accessed 29 November 2011).

Garrison, D. R. \& Vaughan, N.D. (2008). Blearning in higher education - Framework, principles and guidelines. San Francisco: Jossey-Bass.

Graham, C. R. (2004). Blended Learning systems: Definition, current trends, and future directions. In C. J. Bonk \& C. R. Graham (Eds.), Handbook of blended learning: Global perspectives, local designs. San Francisco: Pfeiffer.

Hadji, C. (2001). Avaliação desmistificada. Porto Alegre: Artmed.

Harding, A., Kaczynski, D., \& Wood, L. (2005). Evaluation of blended learning: Analysis of qualitative data. Proceedings of the Symposium of Blended Learning in Science Teaching \& Learning (pp. 56-62). Parramatta, Australia: Australian Associate for Research in Education. 
Hummel, H. (2006). Feedback model to support designers of blended learning courses. International review of Research in Open and Distance Learning, 7(3), 1-16.

Ireland, J., Correia, H. M., \& Griffin, T.M. (2009). Developing quality in e-learning: a framework in three parts. Quality Assurance in Education, 17(3), 250-263.

Jara, M. \& Mellar, H. (2009). Factors affecting quality enhancement procedures for e-learning courses. Quality Assurance in Education, 17(3), 220-232.

Karadeniz, S. (2009). Flexible design for the future of distance learning. Procedia Social and Behavioral Science, 1, 358-363.

Kaznowska, E., Rogers, J., \& Usher, A. (2011). The state of e-learning in Canadian universities, 2011: If students are digital natives, why don't they like e-learning? Toronto: Higher Education Strategy Associates.

Mortera-Gutierrez, F. J. (2004). Faculty best practices using blended learning in e-learning and face-to-face instruction. Proceedings of 20th Annual Conference on Distance Teaching and Learning (pp. 1-6). Madison, Wisconsin, USA.

Parker, N. K. (2008). Quality dilemma in online education revisited. In T. Anderson \& F. Elloumi (Eds.), Theory and practice of online learning ( $2^{\text {nd }}$ ed.) (pp. 385-409). Athabasca University, Athabasca, Canada.

Pombo, L. \& Moreira, A. (2010). Evaluation practices of teaching and learning in Portuguese Higher Education blended learning modules. In M. B. Nunes \& M. McPherson (Eds.). Proceedings of International Conference e-Learning 2010, (pp. 267-274) (Vol 1). Freiburg, Germany.

Pombo, L. \& Moreira, A. (2011a). An evaluation model for blended learning - Evaluation goals, the process and lecturers' perspectives. In António Moreira, Maria José Loureiro, Ana Balula, Fernanda Nogueira, Lúcia Pombo, Luís Pedro, Pedro Almeida (Org.), Proceedings of the 61st International Council for Educational Media and the XIII International Symposium on Computers in Education (ICEM\&SIIE'2011) Joint Conference, "Old meets new -Media in education", (pp. 104-115), University of Aveiro, Aveiro, Portugal.

Pombo, L. \& Moreira, A. (2011b). Assuring and enhancing the quality of blended learning courses reflections of course directors. In M. B. Nunes \& M. McPherson (Eds.), IADIS 2011 Proceedings - International Conference e-Learning 2011, Volume I (pp. 133-140). Rome, Italy.

Pombo, L., Loureiro, M. J., Balula, A., \& Moreira, A. (2009). Diversity of strategies to promote effective b-Learning: a case study in Higher Education. In U. Bernath, A. Szücs, A. Tait, \& M. Vidal (Eds.), Distance and E-learning in Transition - Learning Innovation, Technology and Social Challenges (pp. 627-644). ISTE \& John Wiley \& Sons.

Pombo, L., Loureiro, M. J., \& Moreira, A. (2009). Evaluation Assessment Strategies for Collaborative Learning in a Higher Education blended learning context. Proceedings of EDMEDIA 2009 World Conference on Educational Multimedia, Hypermedia \& Telecommunications (pp. 1848-1857). Honolulu, Hawaii, USA.

Stacey, E. \& Gerbic, P. (2008). Success factors for blended learning. In Hello! Where are you in the landscape of educational technology? Proceedings of Ascilite Melbourne 2008. Retrieved on 1 March 2011 from http://www.ascilite.org.au/conferences/ melbourne08/procs/stacey.pdf 
Ugur, B., Akkoyunlu, B., \& Kurbanoglu, S. (2011). Students' opinions on blended learning and its implementation in terms of their learning styles. Education and Information Technologies, 16, 5-23.

Walker, R. \& Beats, W. (2008). Instructional design for class-based and computer-mediated learning: Creating the right blend for student-centered learning. In R. Donnelly \& F. McSweeney (Eds.), Applied e-learning and e-teaching in higher education, information society reference. New York: Hersey.

Walmsley, L. (2004). How quality assurance can learn from distributed learning. Learning and Teaching in Action, 3(2). Available at: www.celt.mmu.ac.uk/ltia/issue8/walmsley.shtml (assessed 29 November 2011)

Weaver, D., Spratt, C., \& Nair, C. (2008). Academic and student use of a learning management system: implications for quality. Australian Journal of educational technology, 24(1), 30-41.

Correspondence: Lúcia Pombo, Research Centre for Didactics and Technology in Education of Trainers, Department of Education, University of Aveiro, Portugal 